\title{
Assessing an outbreak of tuberculosis in an English college population
}

\section{To the Editors:}

In October 2008, a sixth form college student in England, UK, who had had a cough for 2 months was diagnosed with sputum smear-positive cavitatory pulmonary tuberculosis. An investigation led to the identification of 19 cases of active tuberculosis among 2,284 students. Here, we describe the outbreak and investigation into the factors associated with active tuberculosis.

The study population consisted of students enrolled at the college for daytime courses. All participants were aged $>16$ yrs. Members of staff who directly taught these students were also screened. Between October 2008 and December 2009, students, friends of the index case and staff at the college were interviewed. The interviews were used to collect demographic and clinical information, including symptoms suggestive of tuberculosis. At the same time, a blood sample was drawn from each participant for interferon- $\gamma$ release assay (IGRA) testing [1, 2]. Following the screening of household contacts and friends of the index case, the students at the school were assessed in concentric circles of decreasing intensity of exposure in three groups (table 1) [3]. Those with a positive IGRA result from any screening round were recalled for chest radiography and clinical review at a respiratory medicine clinic. Preventative therapy was offered to all those with no evidence of active tuberculosis and a positive IGRA result who were $<35$ yrs of age, according to national guidelines [4]. Detailed results of the IGRA tests are described elsewhere [5].

Where relevant samples were available, following decontamination, direct microscopy and culture using a liquid culture system were performed and, where positive, subsequent testing for sensitivity to standard antituberculosis drugs, followed by 24-locus Mycobacterium interspersed repetitive unit-variablenumber tandem repeats typing (MIRU-VNTR) [6]. In addition to a detailed clinical review, patients with suspected active tuberculosis had further tests, including computed tomography (CT) and bronchoscopy, where appropriate. Active tuberculosis was defined as any individual with culture-confirmed disease caused by Mycobacterium tuberculosis or a clinical presentation consistent with active tuberculosis where the clinician had decided to give a full 6 months of treatment.

Adjusted and unadjusted odd ratios were calculated using logistic regression analysis to investigate factors associated with active tuberculosis. All variables considered a priori to be risk factors for tuberculosis, including age, sex, place of birth, ethnicity, contact with the index case and lack of bacille Calmette-Guérin (BCG) vaccination, were modelled. We investigated interaction between risk factors for tuberculosis using the likelihood ratio test. Data were analysed using the statistical software STATA (version 11; StataCorp, College Station, TX, USA).
The median age of the students was $17.8 \mathrm{yrs}$ (interquartile range (IQR) 17.3-18.5 yrs) and 1,055 (46.2\%) were male. Among the students, $49.6 \%$ were BCG-vaccinated, $90.2 \%$ were of white ethnicity and $18.8 \%$ had recently travelled to a high-incidence country. The participants travelled to a number of countries, including China, Russia, India, Bangladesh and several countries in sub-Saharan Africa; 400 (17.5\%) had a positive IGRA. The median age of the staff was 46.8 yrs (IQR 38.5-55.3 yrs). No active tuberculosis cases were diagnosed among staff members.

The index case attended the college for $<3$ weeks during September 2008. Excluding the index case, 19 cases of active tuberculosis were diagnosed and treated. Eight cases were culture confirmed as $M$. tuberculosis; seven cases were confirmed as having an indistinguishable 24-locus MIRU-VNTR genotype (42234 2742511334 422423255) as the index case; a further case had 23 identical digits with a missing $24^{\text {th }}$ digit. Of the eight culture-confirmed cases, two were sputum smear and culture positive; one case was sputum smear-negative but culture positive; four cases were positive on culturing washings obtained from bronchoalveolar lavage; and one case was positive on culture of pleural biopsy material. The two sputum smear-positive cases were not symptomatic while attending the college. The diagnosis of cases who were not microbiologically confirmed was largely based on radiological findings, including CT. In total, nine cases were asymptomatic.

During the first two rounds of screening, nine cases of active tuberculosis were identified (including three who were also friends or extended family). Two cases outside the groups screened then presented clinically, prompting a third round of screening that identified a further eight cases. The yield therefore was 3, 2 and $0.5 \%$ in groups 1,2 and 3 , respectively. table 1 shows the characteristics of all cases. All isolates were fully susceptible to first-line antituberculosis drugs. The median age of the active tuberculosis cases was 17.2 yrs (IQR 17$18.3 \mathrm{yrs})$ and $12(63.2 \%)$ out of 19 were male. In the fully adjusted model (table 2), only age was associated with the risk of active tuberculosis, with younger students being at a higher risk of tuberculosis (OR 0.23, 95 CI 0.07-0.75).

This study found that the only independent risk factor for active tuberculosis was age. Although the incidence of tuberculosis has increased in the UK over the last two decades [7], the rate of active tuberculosis identified in this college (875 cases per 100,000 persons) is several times higher than the age-equivalent rate for England (14.6 cases per 100,000). A limitation of the study was the relatively small number of active tuberculosis cases, reducing our ability to investigate the risk factors for active disease. The time taken to screen the entire college possibly contributed to the emergence of secondary cases. 


\section{TABLE 1 Clinical characteristics of active tuberculosis cases}

\begin{tabular}{|c|c|c|}
\hline Case & Clinical details & Group ${ }^{\#}$ \\
\hline 1 & $\begin{array}{l}\text { Symptoms started July } 2008 \\
\text { Smear and culture positive } \\
\text { Treatment started October } 2008\end{array}$ & Index case \\
\hline 2 & $\begin{array}{l}\text { Friend of index case } \\
\text { No symptoms } \\
\text { IGRA positive December } 2008 \\
\text { CXR: right mid-zone nodules } \\
\text { CT scan showed multiple small cavities } \\
\text { BAL smear and culture negative } \\
\text { Treatment started November } 2009\end{array}$ & Group 1 \\
\hline 3 & $\begin{array}{l}\text { Cough and sputum December } 2008 \\
\text { Smear and culture negative } \\
\text { CXR and CT: small nodules right mid-zone } \\
\text { Started treatment February } 2009\end{array}$ & Group 1 \\
\hline 4 & $\begin{array}{c}\text { No symptoms } \\
\text { Smear negative } \\
\text { IGRA positive } \\
\text { BAL culture positive, same genotype } \\
\text { Treatment started April 13, } 2009 \\
\text { Treatment completed October } 2009\end{array}$ & Group 2 \\
\hline 5 & $\begin{array}{c}\text { Smear negative } \\
\text { IGRA positive } \\
\text { CXR in April 2009: right upper zone multiple cavities } \\
\text { BAL culture positive, same genotype } \\
\text { Treatment started April } 2009\end{array}$ & Group 2 \\
\hline 6 & $\begin{array}{c}\text { In same tutor group as another case } \\
\text { IGRA positive } \\
\text { Onset of cough and weight loss in April } 2009 \\
\text { Sputum smear negative } \\
\text { Culture positive, same genotype } \\
\text { CXR normal } \\
\text { Treatment started May } 2009\end{array}$ & Group 2 \\
\hline 7 & $\begin{array}{c}\text { No symptoms } \\
\text { IGRA positive } \\
\text { CXR February } 2009 \text { and CT scan: left hilar gland } \\
\text { and left hilar shadow } \\
\text { Treatment started May } 2009\end{array}$ & Group 2 \\
\hline 8 & $\begin{array}{c}\text { No symptoms } \\
\text { IGRA positive } \\
\text { CXR and CT scan: left upper zone shadowing } \\
\text { BAL culture negative } \\
\text { Treatment started June } 2009\end{array}$ & Group 2 \\
\hline 9 & $\begin{array}{l}\text { Cough, fever, night sweats and weight loss since } \\
\text { December } 2008 \\
\text { GP presentation } \\
\text { Had indeterminate IGRA in April } 2009 \\
\text { Pleural biopsy histology: caseating granulomata } \\
\text { PCR negative } \\
\text { Treatment started May } 2009\end{array}$ & Group 3 \\
\hline 10 & $\begin{array}{l}\text { Cough, weight loss } \\
\text { CXR and CT: left hilar glands } \\
\text { Smear and culture negative } \\
\text { Extended family of index case } \\
\text { Treatment started April } 2009\end{array}$ & Group 3 \\
\hline
\end{tabular}

\section{TABLE 1 cont.}

\begin{tabular}{ccc} 
Case & Clinical details & Group $^{\#}$ \\
\hline 11 & Eye symptoms from June 2009 & Group 3 \\
Choroid tubercles seen & \\
IGRA positive & \\
CXR normal & \\
& Treatment for eye TB started July 2009 & \\
No symptoms & Group 3
\end{tabular}

CXR parenchymal changes and CT scan showed left apex changes

BAL smear negative and culture positive, same genotype

Treatment started September 2009

13 Attended school for a few hours in January and May 2009

Group 3

Diagnosed through GP with cough, sputum, haemoptysis and night sweats which started in April 2009

Smear and culture positive, same genotype

Treatment started August 27, 2009

No respiratory symptoms

Cervical node biopsy in Hong Kong, China

Smear and culture not performed Histological diagnosis

Treated in Hong Kong from April 2009

Cough, night sweats from June 2009 IGRA positive

Group 3

CXR: cavities right upper lobe, sputum smear and culture negative, refused bronchoscopy

Treatment started July 2009

16

$$
\text { No symptoms }
$$

Group 3

CT: left upper zone early cavitation

BAL smear negative and culture positive, same genotype Treatment started July 2009

17

Diagnosed in July 2009 with lymph node disease

CT scan: left lower lobe changes

BAL: smear and culture negative

Treatment started July 2009

18

Cough, night sweats, weight loss

IGRA positive, pleural biopsy

$$
\begin{aligned}
& \text { Smear positive } \\
& \text { PCR negative } \\
& \text { CXR: effusion }
\end{aligned}
$$

Culture positive, same genotype except last digit missing

19

$$
\text { Cough, weight loss in November } 2008
$$

Attended college 2007-2008

CXR and CT: cavities and enlarged hilar nodes

Sputum smear and culture positive, same genotype Treatment started April 2009

20 Fever, night sweats, weight loss, no cough from January 2009

Other

Friend of index case but attended a different college

$$
\text { IGRA positive }
$$

CXR and CT scan: hilar node and parenchymal changes; left lower lobe apical nodule Treatment started July 2009

IGRA: interferon- $\gamma$ release assay; CXR: chest radiography; CT: computed tomography; BAL: bronchoalveolar lavage; GP: general practitioner. ${ }^{*}$ : group 1 included those who shared classroom groups with cumulative exposures $>2 \mathrm{~h}$ with the index case and friends of the index case, group 2 included students who attended the same general studies group with exposure time between 1 and $2 \mathrm{~h}$ in a large hall setting, and group 3 included the rest of the college. 


\begin{tabular}{|c|c|c|c|c|}
\hline TABLE 2 & $\begin{array}{l}\text { nivariable } \\
\text { ctors ass } \\
\text { nong } 2,2\end{array}$ & $\begin{array}{l}\text { Ind multivari } \\
\text { ciated with } \\
\text { students }\end{array}$ & $\begin{array}{l}\text { analysis o } \\
\text { e tuberculo }\end{array}$ & \\
\hline \multirow[t]{2}{*}{ Characteristic } & \multirow{2}{*}{$\begin{array}{l}\text { Median } \\
\text { or } n / N\end{array}$} & \multirow{2}{*}{$\begin{array}{l}\text { Univariable } \\
\text { OR (95\% Cl) }\end{array}$} & \multicolumn{2}{|c|}{ Multivariable } \\
\hline & & & $\begin{array}{c}\text { OR } \\
(95 \% \mathrm{Cl})\end{array}$ & p-value ${ }^{\#}$ \\
\hline Age yrs & 17.2 & $\begin{array}{c}0.27 \\
(0.11-0.67)\end{array}$ & $\begin{array}{c}0.23 \\
(0.07-0.75)\end{array}$ & 0.011 \\
\hline \multicolumn{5}{|l|}{ Sex } \\
\hline Female & $7 / 19$ & 1 & 1 & 0.488 \\
\hline Male & $12 / 19$ & $\begin{array}{c}0.89 \\
(0.73-4.90)\end{array}$ & $\begin{array}{c}1.50 \\
(0.40-5.55)\end{array}$ & \\
\hline \multicolumn{5}{|l|}{ UK born" } \\
\hline No & 2/19 & 1 & 1 & \\
\hline Yes & $17 / 19$ & $\begin{array}{c}0.65 \\
(0.15-2.87)\end{array}$ & & \\
\hline \multicolumn{5}{|c|}{$\begin{array}{l}\text { Travel to high- } \\
\text { burden country }\end{array}$} \\
\hline No & $14 / 19$ & 1 & 1 & 0.200 \\
\hline Yes & $5 / 19$ & $\begin{array}{c}1.81 \\
(0.63-5.17)\end{array}$ & $\begin{array}{c}2.20 \\
(0.55-8.84)\end{array}$ & \\
\hline \multicolumn{5}{|c|}{ White ethnicity } \\
\hline No & $7 / 19$ & 1 & 1 & 0.055 \\
\hline Yes & $12 / 19$ & $\begin{array}{c}0.20 \\
(0.07-0.53)\end{array}$ & $\begin{array}{c}0.26 \\
(0.05-1.43)\end{array}$ & \\
\hline \multicolumn{5}{|l|}{ Group } \\
\hline 1 & & 1 & 1 & 0.371 \\
\hline 2 & & $\begin{array}{c}0.72 \\
(0.19-2.72)\end{array}$ & $\begin{array}{c}2.14 \\
(0.23-20.04)\end{array}$ & \\
\hline 3 & & $\begin{array}{c}0.18 \\
(0.06-0.59)\end{array}$ & $\begin{array}{c}0.60 \\
(0.07-4.96)\end{array}$ & \\
\hline BCG & & & & \\
\hline No & $15 / 19$ & 1 & 1 & 0.780 \\
\hline Yes & $4 / 19$ & $\begin{array}{c}0.38 \\
(0.12-1.25)\end{array}$ & $\begin{array}{c}1.06 \\
(0.22-5.23)\end{array}$ & \\
\hline
\end{tabular}

BCG: bacille Calmette-Guérin. ${ }^{*}$ : likelihood ratio test; " : perfectly predicts outcome in the multivariable model.

While this may, in part, question the "stone in the pond" approach [8], we contend that this incident is unusual. A timeto-event analysis would have been more appropriate to account for right censoring. The lack of dates of contact with infectious cases precluded hazard analysis.

We conclude that this outbreak resulted in transmission within the college, as evidenced by indistinguishable DNA fingerprints of the M. tuberculosis strains. Public health services should ensure the prompt detection and management of such outbreaks.
I. Abubakar*\#\#, T. Matthews",\#\#, D. Harmer ${ }^{\#}$, E. Okereke ", K. Crawford ${ }^{\#}$, T. Hall ${ }^{\#}$, T. Collyns ${ }^{+}$, G. Smith ${ }^{\S}$, A. Barrett ${ }^{f}$ and S. Baugh**

*TB Section, Health Protection Agency (HPA), London, "North Yorkshire and Humber Health Protection Unit, Hull, "HPA Yorkshire and Humber, and ${ }^{+}$Leeds Teaching Hospitals Trust, St James' University Hospital, Leeds, ${ }^{\S} \mathrm{HPA}$ Regional Centre for Mycobacteriology, Birmingham, ${ }^{f} \mathrm{HPA}$ Regional Centre for Mycobacteriology, Newcastle-upon-Tyne, and **Northern Lincolnshire and Goole Hospitals NHS Foundation Trust, Grimsby, UK. ${ }^{\# \#}$ These authors contributed equally.

Correspondence: I. Abubakar, Tuberculosis Section, Health Protection Agency, 61 Colindale Avenue, London, NW9 5EQ, UK. E-mail: ibrahim.abubakar@hpa.org.uk

Support Statement: The investigation was funded by the local National Health Service and the Health Protection Agency as part of the service response to the outbreak and, therefore, no ethical review was required. No external funding was received.

Statement of Interest: None declared.

Acknowledgements: Individuals too numerous to identify were involved in the management of this outbreak, including clinical and administrative support staff from the local health protection unit, primary care trust, acute hospital, local and regional laboratories, and staff and students of the college.

\section{REFERENCES}

1 Kik SV, Franken WPJ, Mensen M, et al. Predictive value for progression to tuberculosis by IGRA and TST in immigrant contacts. Eur Respir J 2010; 35: 1346-1353.

2 Diel R, Goletti D, Ferrara G, et al. Interferon- $\gamma$ release assays for the diagnosis of latent Mycobacterium tuberculosis infection: a systematic review and meta-analysis. Eur Respir J 2011; 37: 88-99.

3 Erkens CGM, Kamphorst M, Abubakar I, et al. Tuberculosis contact investigation in low prevalence countries: a European consensus. Eur Respir J 2010; 36: 925-949.

4 National Collaborating Centre for Chronic Conditions. Tuberculosis: Clinical Diagnosis and Management of Tuberculosis, and Measures for its Prevention and Control. London, Royal College of Physicians, 2009.

5 Abubakar I, Matthews T, Harmer D, et al. Assessing the effect of foreign travel and protection by BCG vaccination on the spread of tuberculosis in a low burden country. Euro Surveill 2011; 16: 19826.

6 Gibson A, Brown T, Baker L, et al. Can 15-locus mycobacterial interspersed repetitive unit-variable-number tandem repeat analysis provide insight into the evolution of Mycobacterium tuberculosis? Appl Environ Microbiol 2005; 71: 8207-8213.

7 Crofts JP, Gelb D, Andrews N, et al. Investigating tuberculosis trends in England. Public Health 2008; 122: 1302-1310.

8 Veen J. Microepidemics of tuberculosis: the stone-in-the-pond principle. Tuber Lung Dis 1992; 73: 73-76.

DOI: 10.1183/09031936.00031711 